\title{
The MCCI (Millon College Counseling Inventory) in an Ethnically Diverse Student Population
}

\author{
Liane Dornheim, R. Ramnath, C. Gomez, H. von Harscher, A. Pellegrini \\ Florida International University, Florida, USA
}

\begin{abstract}
This study examined psychometric properties of the MCCI (Millon College Counseling Inventory) (T. Millon, Strack, C. Millon, \& Grossman, 2006), as applied to students from ethnically and culturally diverse backgrounds. The sample ( $N=209$, Mean age $=23.81,74 \%$ identified as ethnic minority) was derived from students presented for counseling services in a large southeastern state university. Cronbach alpha analyses across all scales were robust; the overall mean alpha coefficient was 0.73 , with the vast majority demonstrating alpha coefficients of 0.70 or higher. An analysis of principal components was conducted, as well to examine the instrument's underlying factor structure. This yielded a seven-component solution explaining $70.15 \%$ of the total variance. Communalities ranged from 0.403 to 0.876 and the rotated component pattern demonstrated simple structure. In summary, when applied to an ethnically diverse sample, the MCCI yielded a performance reflective of the original standardization sample, suggesting its appropriateness for use with an ethnically diverse student body.
\end{abstract}

Keywords: college counseling assessment, multicultural assessment, diversity, ethnicity, MCCI (Millon College Counseling Inventory)

\section{Introduction}

The MCCI (Millon College Counseling Inventory) (Millon et al., 2006) is an objective self-report inventory specifically designed to address personality styles faced by contemporary college counseling populations based on an evolutionary model of personality and psychopathology (Millon \& Davis, 1996). Its normative base is comprised of a stratified sample of students, aged from 16 to 40, seeking mental health services in college and university counseling settings throughout the United States. The instrument was designed to fill a gap in student psychological assessment, as many students now present concerns significantly more ingrained and complex than even a generation ago (e.g., S. A. Benton, Robertson, Tseng, Newton, \& S. T. Benton, 2003; Cornish, Riva, Henderson, Kominars, \& McIntosh, 2000; Erdur-Baker, Aberson, Barrow, \& Draper, 2006).

\section{Millon's Evolutionary Theory and Personality in College Students}

Millon's Evolutionary Theory (Millon, 1990, 2003; Millon \& Davis, 1996) views personality as an evolution-based, centrally-organizing system of perceiving, interpreting and managing demands and

Liane Dornheim, Ph.D., Counseling \& Psychological Services Center, Florida International University.

R. Ramnath, Psy.D., Counseling \& Psychological Services Center, Florida International University.

C. Gomez, Ph.D., Counseling \& Psychological Services Center, Florida International University.

H. von Harscher, Ph.D., Counseling \& Psychological Services Center, Florida International University.

A. Pellegrini, Psy.D., Counseling \& Psychological Services Center, Florida International University. 
psychological stressors, allowing humans to adapt to their environment. Personality, according to Millon's Evolutionary Theory (Millon, 1990; Millon \& Davis, 1996), is a system dedicated to achieving several basic imperatives, or existential "Motivating Aims", following ubiquitous principles shared by all other living entities in the physical world. These principles are represented by a set of three polarities, each marking polar extremes of a given imperative. In brief, these motivating aims include: (1) existence or the polarity of pleasure-pain, meaning the processes of life-enhancement vs. life-preservation; (2) adaptation or tendencies to passively accept or actively modify and confront the environment and its challenges; and (3) replication represented by a self-other polarity, meaning either self-advancement or nurturance. Less adaptive persons tend to exhibit: (1) tenuous stability or a lack of resilience under conditions of stress; (2) an inability to respond flexibly and appropriately to internal and external demands; and (3) a tendency to foster vicious cycles of pathological behavior (Millon, 1969, 1983; Millon \& Davis, 1996). Healthier personalities may also exhibit such tendencies in the direction of their more-favored polarity strategies, especially during significant distress, thereby also affecting their abilities to address circumstances and symptoms (Millon \& Grossman, 2006).

\section{The MCCI: Operationalizing Assessment to Treatment}

The MCCI (Millon \& Davis, 1996; Millon et al., 2006) elucidated a detailed personality description of an individual college student presenting for mental health services on-campus assessing primarily normal personality patterns including ten basic personality style scales and one severe personality pattern scale, followed by a set of scales, "Expressed Concerns", covering degrees of distress expressed by the student in a certain content area. The scale "Clinical Signs" measures Axis I-oriented symptomology (e.g., anxiety, depression and anger). Taken together, these sections allows test users a theoretically cohesive, multidimensional portrait of college counseling clients in terms of their characteristic manners of thinking, feeling and behaving (personality styles), their experienced distress (expressed concerns) and their clinical symptomology (clinical signs). Although the application of Millon's model to college counseling clients is not well researched yet, research in normal adult and psychiatric samples have provided support for many theoretical propositions (Craig, 1999; Strack, 2005; Strack \& Millon, 2007).

Other well-established assessment measures, such as the BDI (Beck Depression Inventory), the SCL-90-R (Symptom Checklist-90-Revised), the BSI (Brief Symptom Inventory) and the Mooney Problem Checklist, have shown to have some limitations when utilized in college counseling settings (Hayes, 1997; Hayes \& Mahalik, 2000; Heppner, Kivlighan, Good, Roehlke, Hills, \& Ashby, 1994; Svanum \& Zody, 2001; Todd, Deane, \& Mckenna, 1997). They used a univariate approach and collecting data primarily from mid-Western, predominantly Caucasian universities, with questionable results regarding of the reliability and validity of a culturally and ethnical diverse student body (Hayes, 1997; Hayes \& Mahalik, 2000; Todd et al., 1997; Svanum \& Zody, 2001; Heppner et al., 1994).

While the MCCI in the normative study which sought inclusiveness of many cultures representative of US subpopulations demonstrated its ability to give reliable and valid multidimensional depiction of a client presenting for mental health services at a college counseling center (Millon et al., 2006), it has been remaining unclear whether its constructs were fully applicable to a highly-diverse population (Grossman, personal communication, March 4, 2008). Clarification in this matter is critical, as researchers, such as Corazzini (1997), have noted that not enough attentions have been given to how the increasing level of pathology among college students seeking mental health services relates to the growing diversity in 
demographics present among university populations. Heppner et al. (1994) revealed in their study that the variable of client ethnicity was strongly associated with higher levels of distress, demonstrating the pressure related to being a member of a minority group within a predominantly white institution and the possible reluctance to use counseling services, unless levels of stress become more intense. To complicate matters, discrepancies between the level of students' reported distress and students' actual distress have been cited in the literature (Kelley, Kahn, \& Coulter, 1996; Solberg, Ritsma, Davis, \& Tata, 1994). The implications of these findings can, therefore, become precarious in working with clients from minority groups, as they may not self-disclose as willingly as Caucasian clients (Morrison \& Downey, 2000). The primary goal, therefore, of the current study is to further examine the validity of the MCCI with a highly diverse, multi-ethnic college counseling population.

\section{Method}

\section{Subjects}

The ethnically diverse sample $(N=209)$ consisted of 88 males and 121 females undergraduate and graduate students aged from 18 to 61 who presented for mental health services at the Counseling and Psychological Services Center of a large Southeastern state university and volunteered at the time of their intake session to participate in the study.

The sample comprised of $78 \%$ undergraduate and 22\% graduate students with a mean age of 23.81 and $74 \%$ of these students belonged to an ethnic minority. Most of them (89.1\%) were enrolled full time and in good academic standards (78.5\%). Two-thirds of the students $(62.8 \%)$ were employed with $84 \%$ of them working part-time (less than 30 hours per week). The 32 MCCI profile scale scores (raw scores) were available for all 209 subjects and scored using the scale compositions and item weighting instructions as described in the MCCI Manual (Millon et al., 2006, p. 73).

\section{Results}

\section{Distribution Characteristics}

With the exception of the scales H-Abusive Experience (skewness 2.01, kurtosis 7.04), AA-Suicidal Tendencies (skewness 1.71, kurtosis 4.54) and JJ-Drug Abuse (skewness 3.46, kurtosis 12.54) which were positively skewed and leptokurtic, all other scales were normally distributed with skewness and kurtosis scores well below 2.5 and Kolmogorov Smirnov tests suggesting normality.

\section{Analyses}

Statistical evaluation included reliability analyses (Cronbach alpha) for the individual profile scales as well as $t$-tests to compare gender mean prevalence scores on the MMCI profile scales of the sample under investigation with the MCCI normative sample. Furthermore, a principal component analysis with Varimax rotation was calculated for the $32 \mathrm{MCCI}$ profile scales using their raw score values.

\section{Results}

The Cronbach alpha coefficients for the profile scales were presented in Table 1 . Across the 32 profile scales, 21 had alpha coefficients of 0.70 or higher, nine had alpha coefficients in the range of 0.60 to 0.69 and two scales (G-Career confusion and J-Living Arrangement Problems) had scores below 0.60 most likely due to the small number of items in these scales. The overall mean alpha coefficient was 0.73 . The Cronbach alpha for 
the V-Validity scale was low (0.40). However, this scale only consisted of three items with two of them having high improbable content ("I have not seen a car in ten years" and "I fly across the Atlantic more than 30 times a year”). The three response style scales, $\mathrm{X}$ (Disclosure), Y (Desirability) and Z (Debasement), are of moderate to high reliability.

Table 1

Coefficient Alpha Reliability Values for the Profile Scales and Scales X, Y and Z

\begin{tabular}{|c|c|c|}
\hline MCCI profile scales & No. of items & Alpha \\
\hline 1. Introverted & 9 & 0.7093 \\
\hline 2A. Inhibited & 9 & 0.7818 \\
\hline 2B. Dejected & 8 & 0.8188 \\
\hline 3. Needy & 7 & 0.7400 \\
\hline 4. Sociable & 8 & 0.7435 \\
\hline 5. Confident & 9 & 0.6144 \\
\hline 6A. Unruly & 9 & 0.6817 \\
\hline 7. Conscientious & 9 & 0.6603 \\
\hline 8A. Oppositional & 8 & 0.6216 \\
\hline 8B. Denigrated & 7 & 0.6907 \\
\hline 9. Borderline & 8 & 0.7933 \\
\hline A. Mental health upset & 8 & 0.8266 \\
\hline B. Identity quandaries & 8 & 0.7057 \\
\hline C. Family disquiet & 5 & 0.6109 \\
\hline D. Peer alienation & 6 & 0.7731 \\
\hline E. Romantic distress & 4 & 0.6387 \\
\hline F. Academic concerns & 4 & 0.7756 \\
\hline G. Career confusion & 3 & 0.5163 \\
\hline H. Abusive experiences & 7 & 0.6308 \\
\hline I. Living arrangement problems & 4 & 0.5519 \\
\hline J. Financial burdens & 4 & 0.7710 \\
\hline K. Spiritual doubts & 4 & 0.7350 \\
\hline AA. Suicidal tendencies & 6 & 0.7708 \\
\hline BB. Depressive outlook & 8 & 0.8358 \\
\hline CC. Anxiety/tension & 4 & 0.7792 \\
\hline DD. Post-traumatic stress & 6 & 0.8127 \\
\hline EE. Eating disorders & 6 & 0.6979 \\
\hline FF. Anger dyscontrol & 7 & 0.7869 \\
\hline GG. Attention (cognitive deficits) & 7 & 0.8239 \\
\hline HH. Obsessions/compulsions & 5 & 0.7408 \\
\hline II. Alcohol abuse & 4 & 0.7523 \\
\hline JJ. Drug abuse & 4 & 0.8970 \\
\hline V. Validity & 3 & 0.3979 \\
\hline X. Disclosure & 9 & 0.5769 \\
\hline Y. Desirability & 22 & 0.9060 \\
\hline Z. Debasement & 58 & 0.6368 \\
\hline
\end{tabular}

Male-female comparisons of mean prevalence scores in the profile scales are presented in Table 2 . The results revealed statistically significant gender differences on seven of the 32 scales. Mean scale scores were much higher for males on the confident, unruly, alcohol abuse and drug abuse scales, while females scored higher on the conscientious, depressive outlook, and eating disorders scales. Similar gender differences were found in the MCCI normative sample (Millon et al., 2006) with males having higher scores on the introverted, confident, unruly, peer alienation, career confusion, oppositional, attention (cognitive deficits) and alcohol abuse scales, and females scoring higher on the conscientious, anxiety/tension and eating disorders scales. 
Table 2

Male-Female Comparison of Mean Prevalence Scores on the Profile Scales

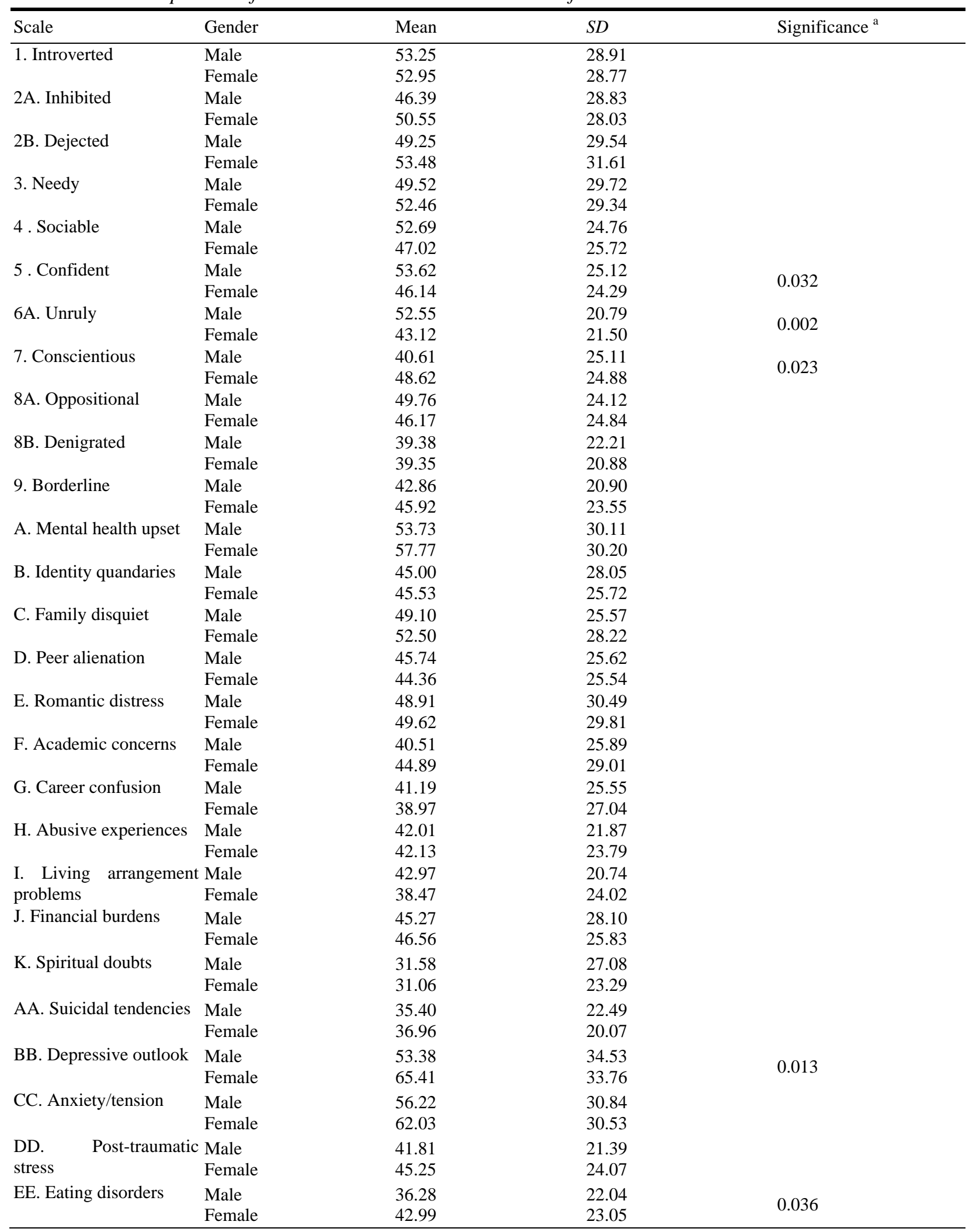


(Table continued)

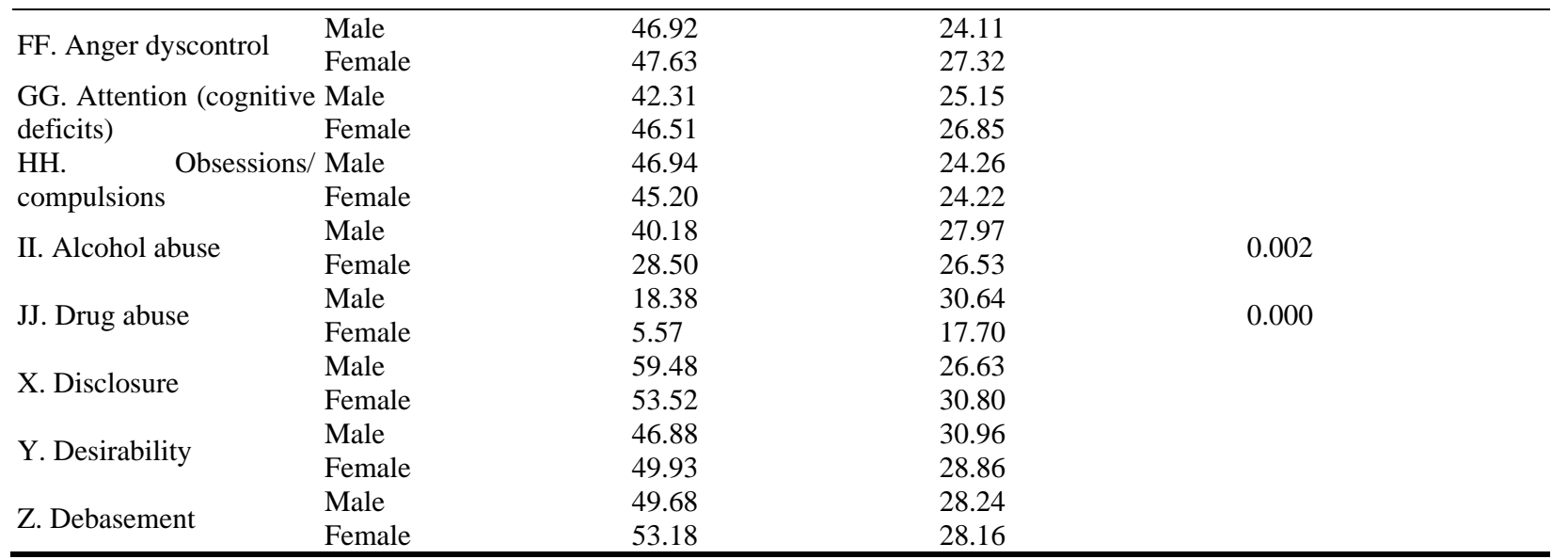

Notes: Male $n=88$; Female $n=121$; ${ }^{\text {a }}$, Two-tailed significance level of the $t$-test comparing male and female means; n. $\mathrm{s} .=$ not significant at $p<0.05$.

To examine the underlying factor structure of the MCCI, a principal component analysis with Varimax rotation was calculated using the raw score values of the 32 clinical scales as suggested by Millon (2001, p. 25) while analyzing the factor structure of a similar instrument, the MBMD (Millon Behavioral Medicine Diagnostic, 2001). The first principal component analysis yielded a seven-component solution explaining $70.15 \%$ of the total variance. Communalities ranged from 0.403 to 0.876 . The results of the MCCI raw score principal component analysis (rotated solution) are presented in Table 3. Factor 1 accounted for $20.38 \%$ of the MCCI variance and was comprised of the scales: 1 -introverted (0.818), 2A-inhibited (0.900), 2B-dejected (0.740), 3—needy (0.653), 4—sociable (-0.810), 8B-denigrated (0.609), B-identity quandaries (0.598), $\mathrm{D}$-peer alienation (0.786) and AA — suicidal tendencies (0.707). The general theme of this component appears to be alienation and/or projective withdrawal. Factor 2 contributed about $15.5 \%$ of the total variance and consisted of the scales: 9-borderline (0.654), A-mental health upset (0.680), BB-depressive outlook (0.659), CC—anxiety/tension (0.694), GG—attention (cognitive) deficits (0.732) and HH—obsessions/compulsion (0.756). The central theme of this component reflects heightened emotional lability and worry. Factor 3 attributed $8 \%$ to the total variance and consisted of the three scales: 7—conscientious (-0.776), II—alcohol abuse (0.774) and JJ—drug abuse (0.730) outlining escapism and/or self-medication. Factor 4 explained $7.2 \%$ of the total variance with contributing scales: being C—-family disquiet (0.547), F-academic concerns (0.593), I-living arrangement problems (0.594) and J-financial burdens (0.689) reflecting environmental conflict. Factor 5 explained another $7.2 \%$ of the total variance and was comprised of the three scales: E-Romantic distress (0.466), H-abusive experiences (0.802) and DD—post-traumatic stress (0.690). The common theme of this component seems to be interpersonal and relational distress. Factor 6 attributed $6.6 \%$ to the total variance with highest loadings on scales: 5-confident (0.728), 6A-unruly (0.661), 8A-oppositional (0.518) and FF-anger dyscontrol (0.642) reflecting aggression and entitlement. Factor 7 explained $5.2 \%$ of the total variance and was comprised of the two scales: G—career confusion (0.623) and $\mathrm{K}$ —spiritual doubts (0.847) outlining existential quandary.

While the rotated component pattern demonstrated simple structure, the following scales raised concerns because of multiple factor loadings: 8A—oppositional (Factors 2 and 7), A—mental health upset (Factors 1 and 2), F-academic concerns (Factors 2 and 4), BB-depressive outlook (Factors 1 and 2) and EE-eating 
disorders (Factor 2 and 5). Therefore, a second principal component analysis with Varimax rotation was calculated without these scales that yielded a seven-factor solution explaining $71 \%$ of variance. Communalities now ranged from 0.883 to 0.519 . However, the second principal component solution only showed slight improvements, it was rejected in favor of the first solution (see Table 4).

Table 3

MCCI Raw Score Principal Component Analysis-Rotated Solution I

\begin{tabular}{|c|c|c|c|c|c|c|c|}
\hline MCCI profile scales & Factor 1 & Factor 2 & Factor 3 & Factor 4 & Factor 5 & Factor 6 & Factor 7 \\
\hline 1. Introverted & 0.818 & 0.176 & 0 & 0 & 0 & 0 & 0.151 \\
\hline 2A. Inhibited & 0.900 & 0.192 & 0 & 0 & 0.17 & 0 & 0 \\
\hline 2B. Dejected & 0.740 & 0.496 & 0 & 0.182 & 0.198 & 0 & 0 \\
\hline 3. Needy & 0.653 & 0.354 & 0 & 0.186 & 0.216 & -0.125 & 0 \\
\hline 4. Sociable & -0.810 & 0 & 0.138 & 0 & 0 & 0.190 & 0 \\
\hline 5. Confident & -0.379 & 0 & 0.193 & -0.139 & 0 & 0.728 & 0 \\
\hline 6A. Unruly & 0.159 & 0.174 & 0.517 & 0.204 & 0.111 & 0.661 & 0 \\
\hline 7. Conscientious & -0.102 & -0.228 & -0.776 & 0 & 0.143 & 0 & -0.200 \\
\hline 8A. Oppositional & 0.279 & 0.464 & 0.236 & 0.385 & 0 & 0.518 & 0 \\
\hline 8B. Denigrated & 0.609 & 0.387 & 0.217 & 0.305 & 0.221 & 0 & 0 \\
\hline 9. Borderline & 0.544 & 0.645 & 0 & 0.158 & 0.87 & 0.151 & 0.103 \\
\hline A. Mental health upset & 0.520 & 0.680 & 0 & 0.163 & 0.164 & 0.110 & 0.125 \\
\hline B. Identity quandaries & 0.598 & 0.382 & 0.215 & 0.116 & 0.272 & 0 & 0.451 \\
\hline C. Family disquiet & 0.297 & 0 & 0 & 0.547 & 0.205 & 0.289 & 0 \\
\hline D. Peer alienation & 0.786 & 0 & 0.145 & 0.105 & 0 & 0.192 & 0 \\
\hline E. Romantic distress & 0.265 & 0.153 & 0.224 & 0.187 & 0.166 & 0 & 0 \\
\hline F. Academic concerns & 0.103 & 0.505 & 0.215 & 0.593 & 0 & -0.239 & 0 \\
\hline G. Career confusion & 0.185 & 0.134 & 0 & 0.375 & 0 & 0 & 0.623 \\
\hline H. Abusive experiences & 0.219 & 0.132 & 0.112 & 0.162 & 0.802 & 0.109 & 0.123 \\
\hline I. Living arrangement problems & 0.121 & 0 & 0.133 & 0.594 & 0.159 & 0.140 & 0.312 \\
\hline J. Financial burdens & 0 & 0.157 & 0 & 0.689 & 0 & 0 & 0 \\
\hline K. Spiritual doubts & 0 & 0 & 0.119 & 0 & 0 & 0 & 0.847 \\
\hline AA. Suicidal tendencies & 0.707 & 0.198 & 0 & 0 & 0.365 & 0.132 & 0 \\
\hline BB. Depressive outlook & 0.541 & 0.659 & 0 & 0.121 & 0.201 & 0 & 0 \\
\hline CC. Anxiety/tension & 0.213 & 0.694 & 0 & 0 & 0.263 & 0.181 & 0 \\
\hline DD. Post-traumatic stress & 0.137 & 0.490 & 0 & 0 & 0.690 & 0.130 & 0.148 \\
\hline EE. Eating disorders & 0.206 & 0.449 & 0.109 & 0.124 & 0.437 & 0 & 0.100 \\
\hline FF. Anger dyscontrol & 0.168 & 0.391 & 0.112 & 0.192 & 0 & 0.642 & 0.168 \\
\hline GG. Attention (cognitive deficits) & 0 & 0.732 & 0.359 & 0.286 & 0 & 0 & 0 \\
\hline HH. Obsessions/compulsions & 0.189 & 0.756 & 0.107 & 0 & 0.209 & 0.158 & 0.179 \\
\hline II. Alcohol abuse & 0 & 0.112 & 0.774 & 0 & 0.149 & 0.168 & 0 \\
\hline JJ. Drug abuse & 0 & 0 & 0.730 & 0 & 0.172 & 0.168 & 0.106 \\
\hline
\end{tabular}

\section{Discussion}

The results indicate that the MCCI is a reliable and valid measure for an ethnically diverse university student population. Similar results regarding reliability were found between the current diverse sample and the original normative sample. The mean reliability for the MCCI presented by Millon (2006) was 0.77 similar to that of the current study (0.73). The lowest reliability score in the normative sample as well as in the current sample was in Career Confusion (0.58 and 0.52 respectively). This consistent finding may be the result of the scale being comprised of just three items. Overall, similar patterns were found in both samples where scales with more items were more reliable and scales with fewer items were, in turn, less reliable.

Similar patterns and differences between genders were found in the current ethnically diverse sample and the normative sample. No significant gender differences were found in either sample with regard to most of the scales. With regard to observed differences, males tended to score higher in the "confident" and "unruly 
personality style" scales as well as the "alcohol abuse clinical" scale in both samples. Females tended to score higher in the "conscientious personality style" scale and the "eating disorders clinical" scale.

Table 4

MCCI Raw Score Principal Component Analysis-Rotated Solution II

\begin{tabular}{lccccccc}
\hline MCCI profile scales & Factor 1 & Factor 2 & Factor 3 & Factor 4 & Factor 5 & Factor 6 & Factor 7 \\
\hline 1. Introverted & 0.820 & 0.148 & 0 & 0 & 0 & 0 & 0.143 \\
2A. Inhibited & 0.910 & 0.162 & 0 & 0.142 & 0 & 0 & 0 \\
2B. Dejected & 0.762 & 0.460 & 0 & 0.193 & 0.158 & 0 & 0 \\
3. Needy & 0.680 & 0.367 & 0 & 0.180 & 0.133 & -0.139 & 0 \\
4. Sociable & -0.806 & 0 & 0.134 & 0 & 0 & 0.185 & 0 \\
5. Confident & -0.384 & 0 & 0.213 & 0 & -0.118 & 0.728 & 0 \\
6A. Unruly & 0.173 & 0.210 & 0.528 & 0.103 & 0.198 & 0.624 & 0 \\
7. Conscientious & 0 & -0.242 & -0.793 & 0.135 & 0 & 0 & -0.202 \\
8B. Denigrated & 0.624 & 0.403 & 0.215 & 0.203 & 0.296 & 0 & 0 \\
9. Borderline & 0.562 & 0.619 & 0 & 0.179 & 0.177 & 0.101 & 0.109 \\
B. Identity quandaries & 0.620 & 0.354 & 0.194 & 0.253 & 0.112 & 0 & 0.461 \\
C. Family disquiet & 0.317 & 0 & 0 & 0 & 0.589 & 0.307 & 0 \\
D. Peer alienation & 0.792 & 0 & 0.149 & 0.109 & 0 & 0.188 & 0 \\
E. Romantic distress & 0.263 & 0.110 & 0.218 & 0.604 & 0 & -0.132 & 0 \\
G. Career confusion & 0.186 & 0.129 & 0 & 0 & 0.420 & 0 & 0.601 \\
H. Abusive experiences & 0.235 & 0.141 & 0 & 0.782 & 0.182 & 0.160 & 0.116 \\
I. Living arrangement problems & 0.117 & 0 & 0.165 & 0.153 & 0.629 & 0 & 0.285 \\
J. Financial burdens & 0 & 0.185 & 0 & 0 & 0.749 & -0.115 & 0 \\
K. Spiritual doubts & 0 & 0 & 0 & 0.116 & 0 & 0.121 & 0.861 \\
AA. Suicidal tendencies & 0.713 & 0.179 & 0 & 0.362 & 0 & 0.128 & 0 \\
CC. Anxiety/tension & 0.241 & 0.736 & 0 & 0.185 & 0 & 0.181 & 0 \\
DD. Post-traumatic stress & 0.157 & 0.505 & -0.119 & 0.663 & 0 & 0.169 & 0.123 \\
FF. Anger dyscontrol & 0.201 & 0.379 & 0.131 & 0 & 0.204 & 0.635 & 0.178 \\
GG. Attention (cognitive deficits) & 0.128 & 0.715 & 0.352 & 0 & 0.169 & 0 & 0.134 \\
HH. Obsessions/compulsions & 0.214 & 0.772 & 0.106 & 0.208 & 0 & 0.121 & 0.180 \\
II. Alcohol abuse & 0 & 0.140 & 0.767 & 0.130 & 0 & 0.168 & 0 \\
JJ . Drug abuse & 0 & -0.114 & 0.743 & 0.162 & 0 & 0.180 & 0 \\
\hline
\end{tabular}

There are some noteworthy differences among samples regarding gender. In the normative sample, males tended to score higher in the "introverted and oppositional personality style" scales, the "peer alienation and career confusion expressed concerns" scales and the "attention (cognitive deficits) clinical" scale. These significant gender differences were not found in the current sample. The inherent differences in the cultural characteristics of the individuals between the two samples might account for the different patterns of gender responses. Multiple cultural and acculturation factors presented in the current sample appear to be contributing to the diminished amount of significant differences between genders as compared to the normative sample. In another distinction, females scored higher than males in the "anxiety/tension clinical" scale in the normative sample, whereas females in the current sample scored higher in the "depressive outlook clinical" scale. Likewise, these differences between samples in clinical presentation of females vs. males might be further attributed to the cultural differences evident between the two samples. In addition to cultural differences between samples, there were age differences between samples. Students in the current sample were older with a mean age of 24 vs. a mean age of 21 in the normative sample. One final potential contributor to the different patterns of gender responses in these variables might be the difference in sample sizes. The normative group was larger and comprised of 564 individuals, whereas the current sample consisted of 209 individuals. Thus, further study with a larger ethnic sample is highly recommended.

According to the Millon's model of test construction, the structure of personality is accessible via 
overarching theoretical means and statistical analysis is used post hoc to substantiate the theory. Thus, the items and structure of the MCCI were derived from theoretical principles. Consistent with this model, a factor analysis was conducted in the current study to explore the factor structure of this theoretically driven instrument. A seven factor model comprised of factors that integrated scales measuring personality types, clinical signs and expressed concerns. Each factor represented a different theoretically cohesive, multidimensional portrait of college counseling clients in terms of their characteristic manner of thinking, feeling and behaving. Thus, the statistical analysis conducted in the current study was consistent with the theoretical premise of the model under which the MCCI was constructed.

\section{Conclusions}

The MCCI is a psychological assessment of college students that purports to address the increasingly complex concerns and personality structures of college students. Given that the application of Millon's model to a college population is relatively new, empirical data examining the hypothesized relationships within this population was non-existent at the time of this study. In addition, although the original normative sample of the MCCI was reasonably successful in collecting minority responses, it remained unclear whether its constructs were fully applicable to a highly-diverse student population. Results of the current study indicated that when applied to an ethnically diverse sample, the MCCI yielded similar results regarding gender differences, reliability and underlying factor structure to that of the original normative sample. Accordingly, it can be concluded that this instrument is a reliable and valid measure for an ethnically diverse student body. Further study with larger ethnic sample is highly recommended.

\section{References}

Benton, S. A., Robertson, J. M., Tseng, W., Newton, F. B., \& Benton, S. L. (2003). Changes in counseling center client problems across 13 years. Professional Psychology: Research and Practice, 34, 66-72.

Corazzini, J. D. (1997). Using research to determine the efficacy of treatment in university counseling centers. Journal of Counseling Psychology, 44, 378-380.

Cornish, J. A. E., Riva, M. T., Henderson, M. C., Kominars, K. D., \& McIntosh, S. (2000). Perceived distress in university counseling center clients across a six-year period. Journal of College Student Development, 41, 104-109.

Craig, R. J. (1999). Overview and status of the Millon clinical multiaxial inventory. Journal of Personality Assessment, 72 , 390-406.

Erdur-Baker, O., Aberson, C. L., Barrow, J. C., \& Draper, M. R. (2006). Nature and severity of college students’ psychological concerns: A comparison of clinical and nonclinical national samples. Professional Psychology: Research and Practice, 37, 317-323.

Hayes, J. A. (1997). What does the brief symptom inventory measure in college and university counseling center clients? Journal of Counseling Psychology, 44, 360-367.

Hayes, J. A., \& Mahalik, J. R. (2000). Gender role conflict and psychological distress in male counseling center clients. Psychology of Men \& Masculinity, 1, 116-125.

Heppner, P. P., Kivlighan, D. M., Good, G. E., Roehlke, H. J., Hills, H. I., \& Ashby, J. S. (1994). Presenting problems of university counseling center clients: A snapshot and multivariate classification scheme. Journal of Counseling Psychology, 41, 315-324.

Kelly, A. E., Kahn, J. H., \& Coulter, R. G. (1996). Client self-presentation at intake. Journal of Counseling Psychology, 43, 300-309.

Millon, T. (1969). Modern psychopathology. Philadelphia: W. B. Sanders.

Millon, T. (1983). Modern psychopathology. Prospect Heights, I. L.: Waveland Press (Original work published 1969).

Millon, T. (1990). Toward a new personology: An evolutionary model. New York: Wiley.

Millon, T. (2003). It’s time to rework the blueprints: Building a science for clinical psychology. American Psychologist, 58, $949-961$. 
Millon, T., \& Davis, R. D. (1996). Disorders of personality: DSM-IV and beyond (2nd ed.). New York: Wiley.

Millon, T., \& Grossman, S. (2006). Resolving difficult clinical syndromes: A personalized psychotherapy approach. New York: Wiley.

Millon, T., Millon, C., Davis, R., \& Grossman, S. (2006). Millon Clinical Multiaxial Inventory-III (MCMI-III) manual (3rd ed.). Minneapolis, M. N.: NCS Pearson.

Millon, T., Strack, S. N., Millon, C., \& Grossman, S. (2006). MCCI manual. Minneapolis, M. N.: NCS Pearson.

Morrison, L. L., \& Downey, D. L. (2000). Racial differences in self-disclosure of suicidal ideation and reasons for living implications for training. Cultural Diversity and Ethic Minority Psychology, 6, 374-386.

Mowbray, C. T., Megivern, D., Mandiberg, J. M., ..., Lett, R. (2006). Campus mental health services: Recommendations for change. American Journal of Orthopsychiatry, 76, 226-237.

Solberg, V. S., Ritsma, S., Davis, B. J., \& Tata, S. P. (1994). Asian-American students' severity of problems and willingness to seek help from university counseling centers: Role of previous counseling experience, gender, and ethnicity. Journal of Counseling Psychology, 41(3), 275-279.

Strack, S. (2005). Measuring normal personality the Millon way. In S. Strack (Ed.), Handbook of personology and psychopathology (pp. 372-389). Hoboken, N. J.: Wiley.

Strack, S., \& Millon, T. (2007). Contributions of the Millon Clinical Multiaxial Inventory (MCMI) and Millon's model to the dimensional assessment of personality disorders. Journal of Personality Assessment, 89(1), 56-69.

Svanum, S., \& Zody, Z. B. (2001). Psychopathology and college grades. Journal of Counseling Psychology, 48, 72-76.

Todd, D. M., Deane, F. P., \& McKenna, P. A. (1997). Appropriateness of SCL-90-R adolescent and adult norms for outpatient and nonpatient college students. Journal of Counseling Psychology, 44(3), 294-301. 